\title{
Hypokalaemic myopathy following ileal resection
}

\author{
Clifford Lawrence \\ M.B., M.R.C.P. \\ Department of Neurology, Leicester Royal Infirmary, Leicester
}

\begin{abstract}
Summary
A patient developed an acute hypokalaemic myopathy due to persistent diarrhoea 4 months after a resection of ileum and a right hemicolectomy for carcinoma of the colon. The need for potassium supplements in the management of chronic diarrhoea following ileal resection is emphasized and the method of potassium replacement discussed.
\end{abstract}

\section{Introduction}

Persistent diarrhoea after ileal resection may cause profound electrolyte disturbance. Potassium homoeostasis is particularly vulnerable as watery diarrhoea contains large quantities of potassium (McColl and Sladen, 1975) and the ability of the kidney to conserve this cation is poor (Lawson, 1976). In these circumstances oral potassium supplements are essential to prevent severe hypokalaemia, which may result in proximal muscle weakness so severe as to cause generalized paralysis. This report concerns a patient who developed an acute hypokalaemic myopathy owing to persistent diarrhoea following a resection of ileum and right hemicolectomy for carcinoma of the colon.

\section{Case history}

A 66-year-old housewife was admitted as an emergency with the sudden onset of generalized muscle weakness. On the day of admission she had been unable to get out of bed or raise herself on her elbows. The day before she had found it impossible to climb stairs and had resorted to moving upstairs one step at a time on her bottom.

Four months earlier she had had a right hemicolectomy for a mucin-secreting adenocarcinoma of the colon. During this operation, approximately $100 \mathrm{~cm}$ of ileum became ischaemic owing to a volvulus at the duodenal-jejunal flexure and had to be resected. There was no evidence of hepatic secondaries and the remaining bowel appeared normal. Postoperatively she developed intractable watery diarrhoea occurring up to five times a day. Subsequent barium studies showed no evidence of fistula formation. A laparotomy 6 weeks later revealed a normal ileocolic anastomosis with noo evidence of recurrence, fistula, stricture or pan- $\frac{0}{3}$ creatic tumour. Steatorrhoea was not present $\frac{3}{i j}$. (faecal fat $3.2 \mathrm{~g} / 24 \mathrm{hr}$ ) and the serum vasoactiveo intestinal peptide concentration was normal. At- 9 tempts to control the diarrhoea with cholestyra-. mine were unsuccessful. Before admission she hade्ध been taking antispasmodics but no other medication. $\circ$

On examination she had a severe proximal $^{\circ}$ muscle weakness and was only just able to lift her $\vec{z}$ head off the pillow. There was no fasciculation, muscle wasting or sensory disturbance; tendon $\widehat{S}$ reflexes were present and equal. Chvostek's sign wass $\vec{\bullet}$ negative and there was no main d'accoucher General examination was normal. She appeared ${ }^{N}$ adequately hydrated; her blood pressure $110 / 80 \mathrm{mmHg}$.

Investigations showed plasma sodium $140 \mathrm{mmol} / 1 ; \overline{\bar{O}}$ potassium $2.0 \mathrm{mmol} / \mathrm{l}$; urea $13.0 \mathrm{mmol} / \mathrm{l}$; calciumo $1.88 \mathrm{mmol} / \mathrm{l}$; phosphate $6.9 \mathrm{mmol} / \mathrm{l}$; alkaline phos- $\varrho$ phate 246 i.u./l (normal 60-260); albumin $31 \mathrm{~g} / \mathrm{l} . \overrightarrow{\vec{O}}$ Muscle enzymes showed a raised creatine-kinase 3 (CK) 383 i.u./l (normal 25-200), consistent with a degree of muscle necrosis. Electromyography con-0. firmed the presence of a myopathy. An electrocardiogram (ECG) showed flattened $T$ waves, a 3 . prominent $U$ wave and a sagging $S T$ segmento consistent with hypokalaemia.

Oral effervescent potassium chloride $(96 \mathrm{mmol} / \hat{\circ}$ day) and effervescent calcium gluconate $(100 \mathrm{mmol} / \beta$ day) were started. Within $24 \mathrm{hr}$ she was able to sito up in bed unaided. The following day she was able to walk and rise from a low chair unaided. At thiso. time her plasma potassium was $3.9 \mathrm{mmol} / \mathrm{l}$ and calcium $2.1 \mathrm{mmol} / 1$. Her ECG had returned to ${ }^{\infty}$ normal.

Subsequently, her diarrhoea was controlled with $\mathcal{E}^{-}$ antispasmodics and a low fat diet with addedo protein and carbohydrate. Potassium supplement were continued. A trial of oral tetracycline did not produce any further improvement.

Discussion

The average potassium intake is $60-100 \mathrm{mmol} / \mathbb{R}^{\circ}$ 
day (Lawson, 1976), most of which is excreted in the urine. Normal stools and sweat contain only $5 \mathrm{mmol} /$ day of potassium; liquid stool contains 40-60 mmol/l. Unlike sodium, potassium conservation by the kidney is poor, and minimal excretion is not achieved until 7 days of negative potassium balance (Black and Milne, 1952).

Hypokalaemia may be asymptomatic, especially if mild and gradual in onset. More acute potassium depletion causes generalized muscle weakness. Very severe hypokalaemia may lead to virtual total paralysis (Editorial, 1980). The present patient showed the characteristic pattern of weakness, associated with biochemical evidence of muscle necrosis indicated by a raised CK and a myopathic electromyographic appearance. The rapid and complete response to potassium replacement is characteristic.

Potassium replacement therapy is best given by mouth as this avoids the possibility of a sudden increase in serum potassium concentration following a too rapid infusion. Effervescent potassium chloride $(12 \mathrm{mmol} /$ tablet $)$ and slow release potassium chloride $(8 \mathrm{mmol} /$ tablet $)$ are the most useful preparations. A total dose of $40-60 \mathrm{mmol} /$ day is sufficient. Intravenous replacement may be required in a life-threatening situation. In general, the infusion rate should not exceed $10 \mathrm{mmol} / \mathrm{hr}$ and the total infusion should be less than $120 \mathrm{mmol} / 24$ hr (Lawson, 1976), although higher rates of infusion may be life-saving in severely depleted states (Pullen, Doig and Lambie, 1967). Concentrations of potassium chloride in excess of $40 \mathrm{mmol} / \mathrm{l}$ cause painful spasm of the vein. If potassium is given in a glucose solution there may be a transient fall in serum potassium owing to the intracellular movement of potassium ions during glucose metabolism (Kunin, Surawicz and Sims, 1962). This may be significant in patients taking digoxin or those with severe potassium depletion.

Calcium salts were given with potassium replacements to avoid tetany. Hypokalaemia and hypocalcaemia may occur simultaneously in the malabsorption syndrome. The neuromuscular effect of each electrolyte abnormality then obscures the other and treatment of either disorder alone will precipitate symptoms of the untreated deficiency. Several factors may cause hypocalcaemia. Firstly, this could be a result of osteomalacia secondary to the malabsorption of fat soluble vitamin D. Osteomalacia is associated with muscle weakness (Schott and Wills, 1976) which is of gradual onset and not related to the serum calcium concentration (Smith and Stern, 1967). There was no other biochemical or radiographic evidence of osteomalacia in the patient. Secondly, the precipitation of calcium salts as soap by fatty acids has been suggested as contributing to poor calcium absorption in patients with malabsorption (Agnew and Holdsworth, 1971). This seems to be a possible mechanism in the present patient. Finally, in some malabsorption states such as coeliac disease, endogenous calcium secretion is very high (Duthie and Wormsley, 1979).

Ileal resections greater than $100 \mathrm{~cm}$ may cause steatorrhoea; this was not present in the patient. Shorter resections are likely to result in bile acid malabsorption. Free bile acids then stimulate the colonic secretion of water and electrolytes causing watery diarrhoea, which may respond to the use of the bile acid binding agent cholestyramine (Hofman and Poley, 1972). Neither mechanism appeared to be the principle cause of the patient's diarrhoea. A trial of oral tetracycline was not effective; this suggests that bacterial overgrowth was not a contributory factor. It was concluded that the diarrhoea was a result of an inadequate absorptive surface; the mechanism of which is thought to be the cathartic effect of hydroxy fatty acids produced by the bacterial degradation of non-absorbed long chain fatty acids (Ammon, Thomas and Phillips, 1974). The object of this report is to emphasize the need for adequate potassium supplements in the management of persistent diarrhoea following ileal resection.

\section{References}

Agnew, J.E. \& Holdsworth, C.D. (1971) The effect of fat on calcium absorption from a mixed meal in normal subjects, patients with malabsorptive disease and patients with partial gastrectomy. Gut, 12, 973.

Ammon, H.V., Thomas, P.J. \& Phillips, S.F. (1974) Effects of oleic and ricinoleic acids on net jejunal water and electrolyte movement. Journal of Clinical Investigation, 53, 374.

BlACK, D.A.K. \& MiLne, M.D. (1952) Experimental potassium depletion in man. Lancet, i, 244.

DuthIE, H.L. \& WoRMSLEY, K.G. (Eds) (1979) Scientific Basis of Gastroenterology, 1st edn, p. 378. Churchill Livingstone, London.

Editorial (1980) Severe hypokalaemia. Lancet, i, 520.

Hofman, A.F. \& Poley, J.R. (1972) Role of bile acid malabsorption in pathogenesis of diarrhoea and steatorrhoea in patients with ileal resection. Gastroenterology, 62, 918.

Kunin, A.S., Surawicz, B. \& Sims, E.A.H. (1962) Decrease in serum potassium concentrations and appearance of cardiac arrhythmias during infusion of potassium with glucose in potassium-depleted patients. New England Journal of Medicine, 266, 228.

Lawson, D.H. (1976) Potassium therapy. British Journal of Hospital Medicine, 16, 392.

McColl, I. \& Sladen, G.E.G. (Eds) (1975) Intestinal Absorption in Man, 1st edn, p. 81. Academic Press, London.

Pullen, H., Doig, A. \& Lambie, A.T. (1967) Intensive intravenous potassium replacement therapy. Lancet, ii, 809.

SchotT, G.D. \& Wills, M.R. (1976) Muscle weakness in osteomalacia. Lancet, i, 626.

Smith, R. \& Stern, G. (1967) Myopathy, osteomalacia and hyperparathyroidism. Brain, 90, 593. 